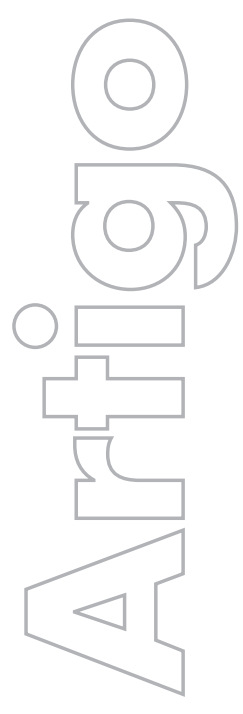

\title{
Emissões fugitivas de metano em aterros sanitários
}

\author{
Giovano Candiani \\ Unifesp \\ Ednilson Viana \\ USP
}

\section{revista}

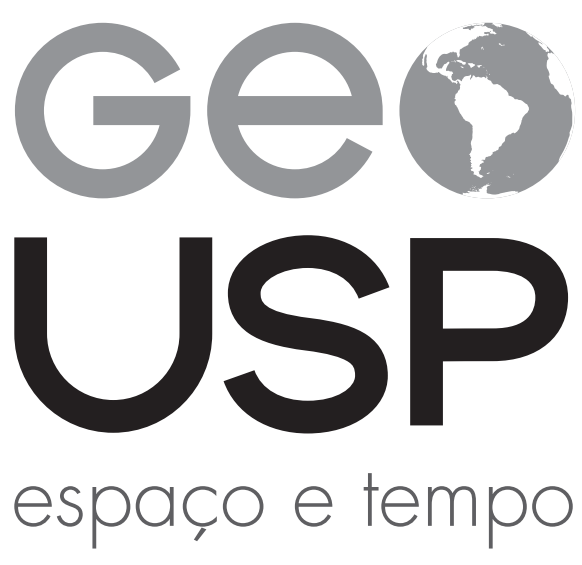

Volume $21 \cdot n^{\circ} 3(2017)$
Como citar este artigo:

CANDIANI, G.; VIANA, E. Emissões fugitivas de metano em aterros sanitários. Geousp - Espaço e Tempo (Online), v. 21, n. 3, p. 845-857, dez. 2017. ISSN 2179-0892.

Disponível em: <http://www.revistas.usp.br/geousp/ article/view/97398 > . doi: 10.11606/issn.2179-0892. geousp.2017.97398.

\section{(c) $(1)(9)$}

Este artigo está licenciado sob a Creative Commons Attribution 4.0 License. 


\title{
Emissões fugitivas de metano em aterros sanitários
}

\begin{abstract}
Resumo
A quantidade de metano emitida dos aterros sanitários à atmosfera é controlada pelo tipo de camada de cobertura sobre o aterro. As medições da emissão de metano foram realizadas utilizando o método da placa de fluxo, e o objetivo deste estudo foi estimar as emissões de metano a partir da superfície do aterro sanitário. Os resultados mostram que as emissões fugitivas de metano na atmosfera são de $18,66 \mathrm{~g} / \mathrm{m}^{2} /$ dia a $149,86 \mathrm{~g} / \mathrm{m}^{2} /$ dia, representando $31,4 \%$ da produção total de metano no aterro sanitário. A eficiência de captação de gás no aterro foi de 68,6\%. A emissão fugitiva é o resultado da ineficiência do sistema de captação de gás no aterro sanitário.
\end{abstract}

Palavras-chave: Resíduos sólidos. Aterro sanitário. Metano. Emissão fugitiva. Camada de cobertura.

\section{Methane fugitive emissions at landfills}

\begin{abstract}
The amount of methane emitted from landfills to the atmosphere is controlled by the type of cover layer on the landfill. The methane flux measurements were performed using a static chambre technique. The objective of this study was to estimate the emissions of methane from the landfill surfasse. The results show that fugitive emissions of methane into the atmosphere are $18.66 \mathrm{~g} / \mathrm{m}^{2} /$ day to $149.86 \mathrm{~g} / \mathrm{m}^{2} /$ day, representing $31.4 \%$ of the total methane production in the landfill. The gas capture efficiency in the landfill was $68.6 \%$. The fugitive emission is the result of the inefficiency of the gas capture system in the landfill.
\end{abstract}

Keywords: Waste solid. Landfill. Methane. Fugitive emission. Cover layer.

\section{Introdução}

aterro sanitário é uma técnica de disposição final de resíduos sólidos no solo, que utiliza critérios de engenharia para não causar danos à saúde pública e ao meio ambiente. Os aterros sanitários são empreendimentos, que para serem instalados dependem de licenciamento ambiental, realizado por meio da elaboração de um estudo de impacto ambiental, sendo estes implantados somente depois de constatada sua viabilidade ambiental pelo órgão público licenciador (Barros, 2013). 
Estima-se que o Brasil produziu, em 2015, aproximadamente 80 milhões de toneladas de resíduos sólidos, sendo 60\% dispostos em aterros sanitários e 40\% em aterros controlados e lixões, que não são formas adequadas de disposição final e causam impactos ambientais com a poluição do solo, recursos hídricos e ar (Abrelpe, 2016).

O cenário atual de gerenciamento dos resíduos sólidos no Brasil ainda é precário e preocupante, mesmo com o sancionamento da Política Nacional de Resíduo Sólido, Lei Federal no 12.305, de 2 de agosto de 2010 (Brasil, 2010), estabelecendo princípios para o gerenciamento integrado (dimensões política, econômica, social e ambiental), valorização ambiental e energética dos resíduos sólidos (Barros, 2012).

Um aterro sanitário é uma obra de engenharia, que exige cuidados específicos para minimizar a ocorrência de impactos ambientais. A implantação inicia-se com a impermeabilização do solo, que é realizada por meio da compactação de camadas de argila e pela aplicação de geomembrana (produto polimérico sintético de baixíssima permeabilidade) e instalações de sistemas de drenagem das águas pluviais, lixiviados e gases (Candiani; Moreira, 2015).

$\bigcirc$ processo de biodegradação anaeróbia do resíduo sólido e a consequente emissão de biogás no aterro sanitário variam ao longo do tempo, pois dependem de uma sequência de etapas envolvendo complexas interações com fatores físico-químicos e biológicos, critérios do projeto de engenharia e parâmetros, como: característica e idade do resíduo, sistema operacional do aterro sanitário, camada de cobertura, localização geográfica e condições climáticas (Abreu, 2014; Gonzalez-Valencia et al., 2016).

Nesse contexto, avaliar as emissões de biogás (gases de efeito estufa) e seus efeitos ambientais (mudanças climáticas), bem como os impactos da própria presença dos aterros sanitários na paisagem, modificando-a pela disposição de resíduos sólidos no solo e demais interfaces relacionadas com essas problemáticas, como: a geração de resíduos sólidos nos municípios e a cultura do consumismo são discussões fundamentais no âmbito da Geografia Crítica e Ecológica, pois podem refletir em mudanças nos processos produtivos, tornando-os mais sustentáveis e consequentemente melhorar a qualidade de vida na sociedade em geral (Souto, 2016).

$O$ biogás de aterro sanitário é composto principalmente pelo $\mathrm{CO}_{2}(40 \%), \mathrm{CH}_{4}(55 \%)$ e outros gases (5\%), como: $\mathrm{NH}_{3}, \mathrm{H}_{2} \mathrm{~S}, \mathrm{O}_{2}, \mathrm{CO}, \mathrm{N}_{2}$ etc. Normalmente, os gases são captados por meio de um sistema de drenagem, constituído por drenos verticais instalados em diferentes pontos do aterro sanitário. Os drenos verticais são formados por tubos, que em suas extremidades são instalados queimadores de gases, com a finalidade de evitar o escape de metano para a atmosfera (Abreu, 2014). Os aterros sanitários instalados mais recentemente apresentam sistemas de captação de biogás interligados a centrais termoelétricas, que produzem energia elétrica por meio da queima do gás metano em motores (Candiani; Moreira, 2015; Teixeira Junior, 2016).

A cobertura dos resíduos sólidos é o principal sistema para evitar ou minimizar as emissões de biogás nos aterros sanitários. No Brasil, geralmente utiliza-se uma camada de solo compactada sobre os resíduos sólidos, que funciona como uma barreira. Entretanto, devido às condições climáticas, com ciclos de umedecimento e secagem, esta camada de solo acaba perdendo sua eficiência, ocorrendo o escape fugitivo de gás pela superfície do aterro sanitário (Mariano; Jucá, 2010).

É comum em muitos países, o uso da geomembrana como camada de cobertura final nos aterros sanitários, reduzindo as emissões superficiais de gás (Lando; Nakayama; Shimaoka, 2017; Lucernoni et al., 2016). 


\section{Estimativas para a medição do fluxo de gases pelas camadas de cobertura em aterro sanitário}

Em geral, a quantificação das emissões de gases pela superfície em aterro sanitário é bastante complicada e complexa, não existindo um método amplamente aceito (Lucernoni et al., 2016; Lando; Nakayama; Shimaoka, 2017; Gonzalez-Valencia et al., 2016).

Os aterros sanitários são considerados fontes importantes de emissão de gases de efeito estufa, principalmente em relação ao gás metano, que é também um valioso recurso energético, daí a importância em se determinar seu fluxo superficial no aterro sanitário (Park; Kang; Lee, 2016).

Existem vários métodos para a medição do fluxo de metano pela camada de cobertura em aterro sanitário, os principais métodos são: placa de fluxo, dinâmica e mapeamento de pluma, traçador de gases, sensores a laser etc. (Lucernoni et al., 2016).

A dinâmica de mapeamento de pluma é um método baseado na instrumentação, utilizando sensores ópticos remotos, que medem concentração de gases no aterro sanitário (Babilotte et al., 2010).

traçador de gases é uma técnica que consiste em medir concentrações simultâneas de metano e direção do vento no aterro sanitário, utilizando como parâmetro um traçador de gás inerte, como $\circ \mathrm{N}_{2} \mathrm{O}$ (óxido nitroso). Com estas informações, determina-se por meio de modelagem numérica matemática de dispersão, os fluxos de metano emitidos pelo aterro sanitário (Goldsmith Junior et al., 2012).

A técnica baseada na aplicação de laser permite a realização das medições de concentrações de metano com grandes alcances, sendo necessário o uso de veículos com equipamentos de apoio (Scheutz et al., 2011; Battaglini; Raco; Scozzari, 2013; Monster et al., 2014; Gallego et al., 2014; Park; Kang; Lee, 2016).

Porém, a utilização dessas técnicas exige equipamentos/sistemas complexos e elevados investimentos (Lando; Nakayama; Shimaoka, 2017; Park; Kang; Lee, 2016).

O método da placa de fluxo é relativamente simples e barato, sendo uma técnica apresentada na literatura como eficiente para medir o escape fugitivo de gás metano em aterro sanitário (Mariano; Jucá, 2010; Schroth et al., 2012; Lucernoni et al., 2016; Park; Kang; Lee, 2016).

Medições com placa de fluxo apontam para taxas de emissões superficiais de metano em aterro sanitário da ordem de 0,0001 g/m²/dia a $1000 \mathrm{~g} / \mathrm{m}^{2} / \mathrm{dia}$ (Abichou et al., 2009; Gonzalez-Valencia et al., 2016; Lando; Nakayama; Shimaoka, 2017), grandes variações atribuídas a inúmeros fatores, como: camada de cobertura, característica e idade dos resíduos, além de aspectos climáticos (Mariano; Jucá, 2010).

Assim, este trabalho apresenta como objetivo estimar as emissões fugitivas de metano em aterro sanitário, subsidiando aperfeiçoamentos em relação ao gerenciamento de gás metano em aterro sanitário.

\section{Área de estudo}

O estudo foi realizado no Aterro Sanitário Caieiras, localizado no município de Caieiras (23०21'51'S e 46॰44'26" W) no estado de São Paulo, Brasil (Figura 1). 


\section{Figura 1 - Localização do Aterro Sanitário Caieiras}

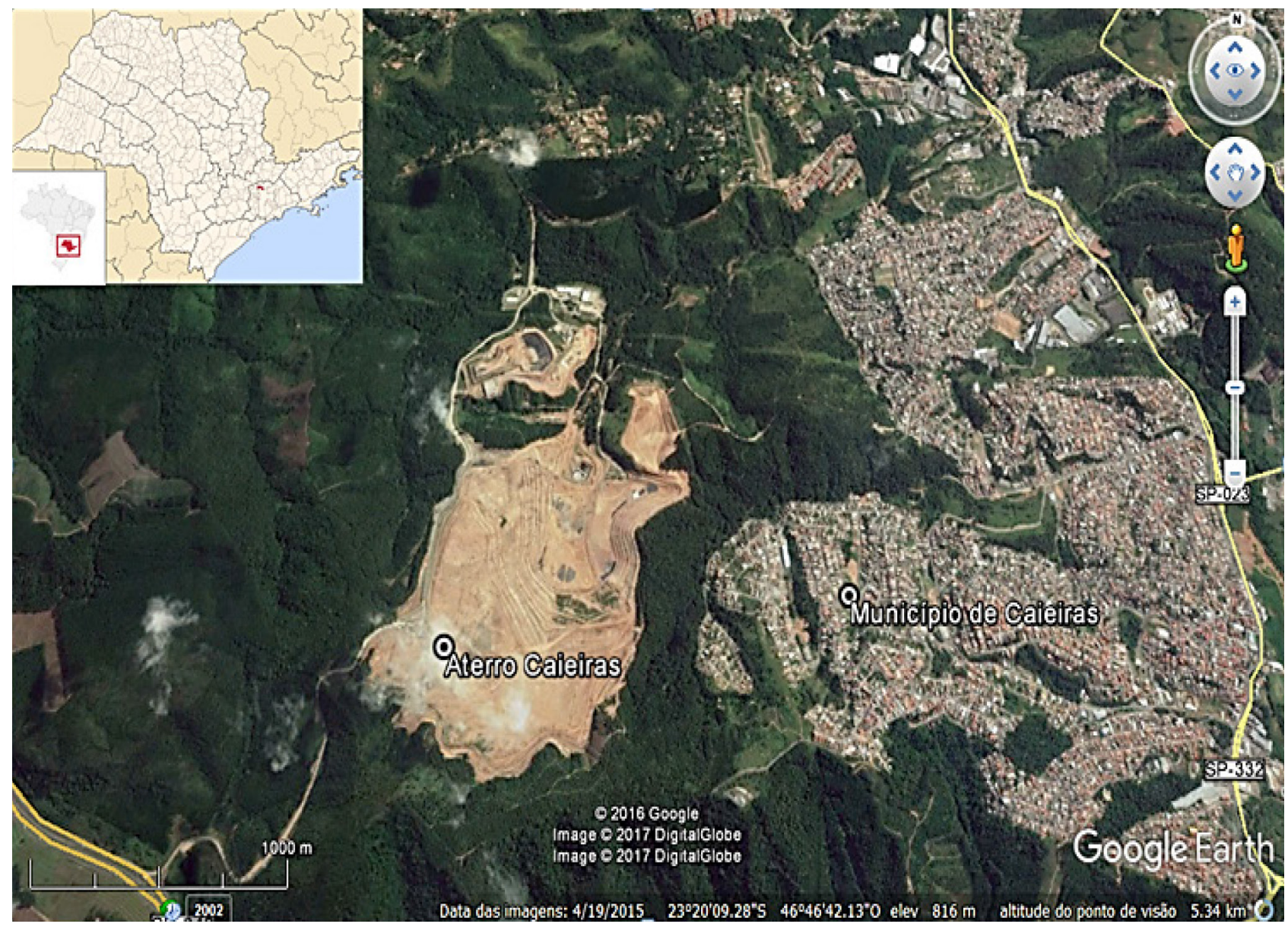

fonte: Acervo pessoal dos autores.

município de Caieiras se situa na Região Metropolitana de São Paulo (RMSP), tem uma área de $95,89 \mathrm{~km}^{2}$ e população de 86.623 habitantes. Está inserido em uma região de clima regional do tipo Cwa, temperado úmido com verões chuvosos e invernos secos, conforme a classificação de Köppen. A precipitação média anual é de $1.450 \mathrm{~mm}$, a temperatura média do ar durante o ano é de $18^{\circ} \mathrm{C}$, com mínima média de $13,5^{\circ} \mathrm{C}$ e máxima média de $22^{\circ} \mathrm{C}$, o relevo acentuado influencia fortemente o clima na região. A região encontra-se no Planalto Atlântico, mais precisamente na Zona Serrania de São Roque, o solo é siltoso e as altitudes variam de $1.100 \mathrm{~m}$ (topos e encostas) a $750 \mathrm{~m}$ nos fundos de vale (Essencis, 2016).

A Aterro Sanitário Caieiras (Figura 2) ocupa uma área de 350 hectares. Sua operação foi iniciada em 2002 e, atualmente, recebe aproximadamente 7.000 toneladas/dia de resíduos sólidos urbanos, provenientes principalmente do município de São Paulo. No período de 2002 a 2014, o aterro já tinha recebido aproximadamente 26 milhões de toneladas de resíduos, perfazendo um maciço sanitário de cerca de $90 \mathrm{~m}$ de altura. Os resíduos recebidos são compactados e recobertos com uma camada de solo com espessura de 0,5 m. $\bigcirc$ lixiviado coletado pelas tubulações é armazenado em bacias de contenção e, posteriormente transportado (caminhão tanque) para tratamento na unidade de Barueri da empresa SABESP. $\bigcirc$ Aterro Sanitário Caieiras tem cerca de 140 drenos verticais e produz aproximadamente $7.000 \mathrm{~m}^{3} / \mathrm{h}$ de gás metano. $\bigcirc$ gás captado pelo aterro sanitário é encaminhado à termoelétrica, que produz $30 \mathrm{MWh}$ de energia elétrica (Essencis, 2016). 
Figura 2 - Aterro Sanitário Caieiras

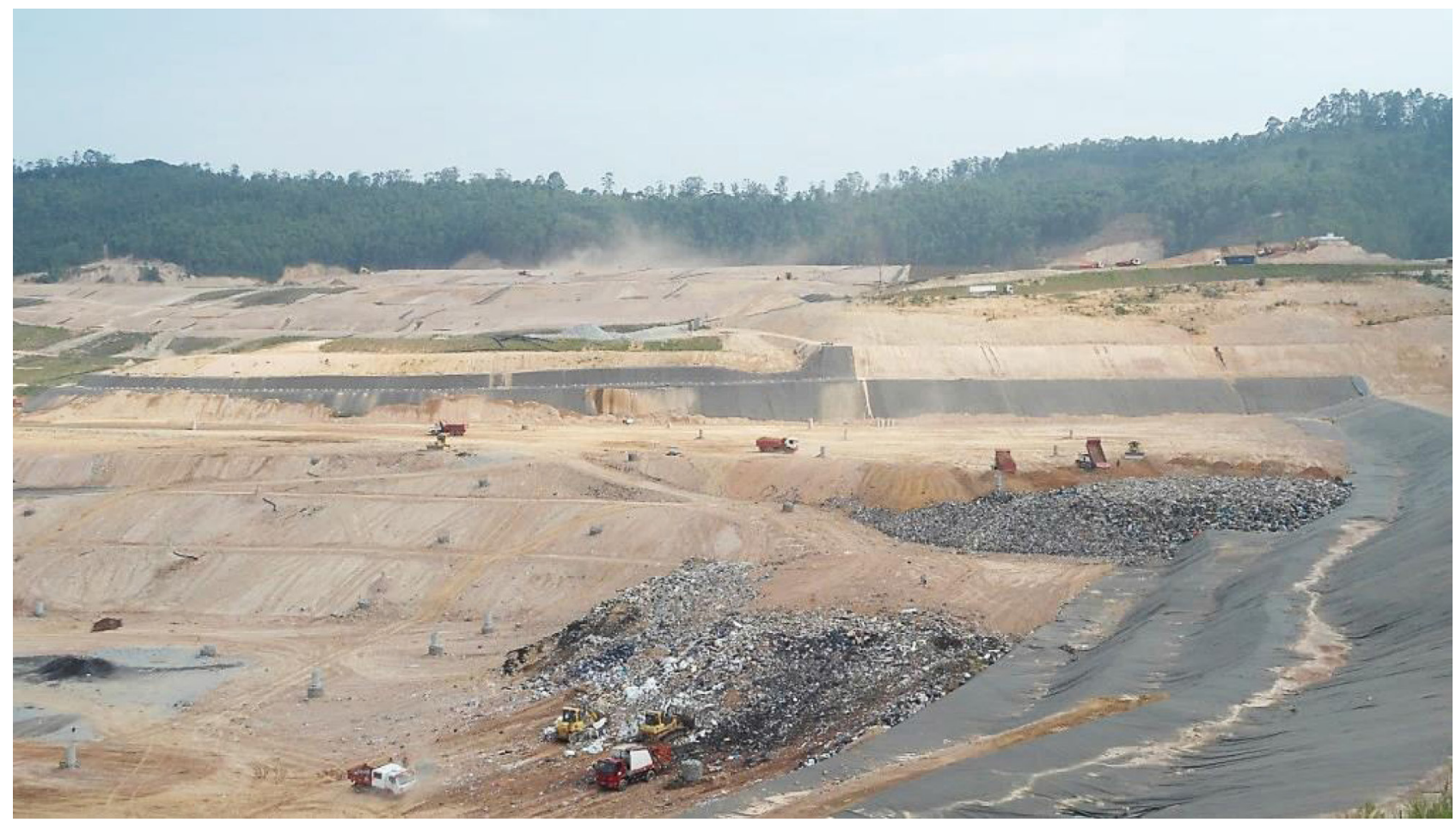

fonte: Acervo pessoal dos autores.

\section{Método}

A estimativa da emissão fugitiva de metano no aterro sanitário foi realizada utilizando-se o método da placa de fluxo (Figura 3).

Figura 3 - Medição com a placa de fluxo do escape fugitivo de metano no aterro sanitário

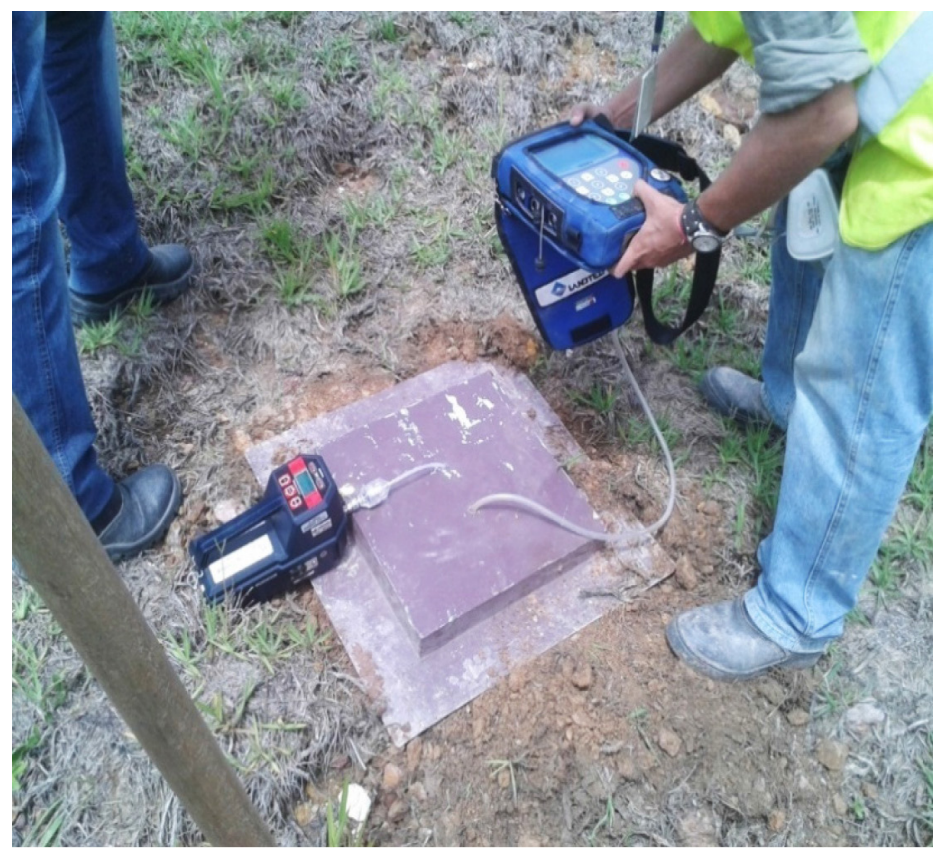

fonte: Acervo pessoal dos autores. 
A placa de fluxo foi construída com chapa de aço galvanizado com $1 \mathrm{~mm}$ de espessura, apresentando um degrau para evitar a entrada de ar atmosférico no interior da caixa. No topo da placa existem duas conexões de saída, nas quais são conectados os equipamentos de medição. A placa apresenta as seguintes medidas: 0,50 $\mathrm{m} \times 0,50 \mathrm{~m} \times 0,05 \mathrm{~m}$, porém o volume útil de amostragem é de $0,40 \mathrm{~m} \times 0,40 \mathrm{~m} \times 0,05 \mathrm{~m}$, pois $0,10 \mathrm{~m}$ formam flanges nos lados da placa, que é colocada na superfície do aterro e coberta com solo, evitando o escape de gás pelas bordas da placa. Assim, o volume de coleta de gás é de 0,008 $\mathrm{m}^{3}$ e a área é de $0,16 \mathrm{~m}^{2}$.

$\bigcirc$ procedimento de medição com a placa de fluxo foi o seguinte: o local amostrado no aterro sanitário foi preparado, utilizando-se uma enxada para adequar o terreno, em seguida a placa de fluxo foi colocada na superfície do aterro sanitário e suas bordas preenchidas com solo, com os equipamentos acionados foram realizadas as medições, anotando-se as concentrações de metano, intervalos de tempo e os valores de pressão e temperatura (Mariano; Jucá, 2010; Maciel; Jucá, 2011; Candiani; Moreira, 2015).

Foram realizadas medições em 4 fases operacionais do aterro sanitário. Essas fases juntas representam uma área de $430.000 \mathrm{~m}^{2}$. No total foram realizadas 480 medições do escape fugitivo superficial no aterro sanitário, ou seja, 120 medições por fase, distribuídas nos meses de março-abril e setembro-outubro de 2014 (Figura 4).

\section{Figura 4 - Pontos de medição do escape fugitivo de metano nas fases do aterro sanitário}

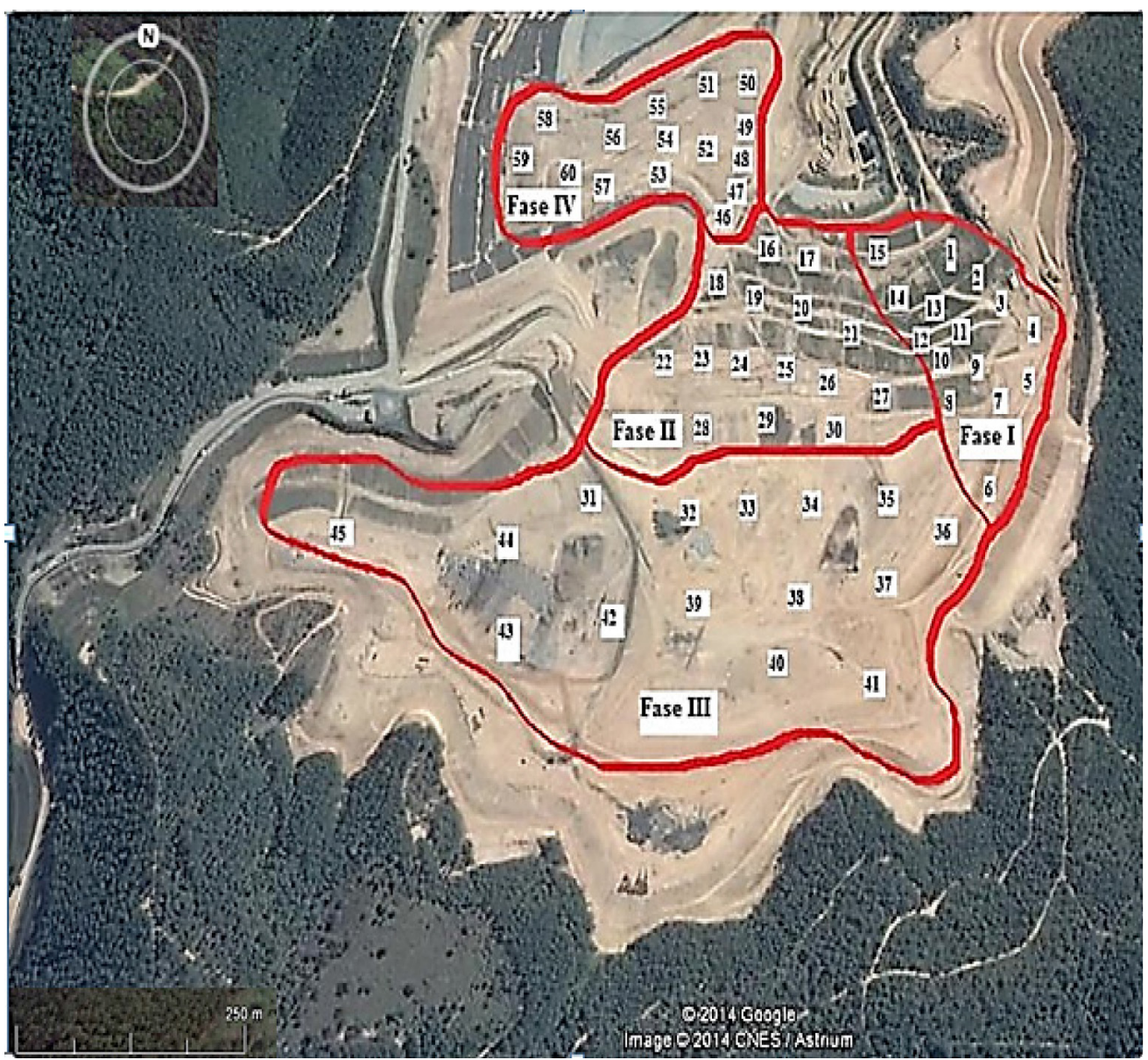

fonte: Acervo pessoal dos autores. 
O fluxo de metano na superfície do aterro sanitário foi determinado pela coleta de gás na placa de fluxo em um dado intervalo de tempo, conforme a Equação 1 (Mariano; Jucá, 2010; Lucernoni et al., 2016; Lando; Nakayama; Shimaoka, 2017; Gonzalez-Valencia et al., 2016):

$$
F=\rho \frac{V}{A} \frac{\Delta C}{\Delta t} \frac{M M P}{R T} \quad \text { Equação } 1
$$

em que:

F: fluxo de metano $\left(\mathrm{g} / \mathrm{m}^{2} / \mathrm{h}\right)$;

$\rho$ : densidade do gás metano $\left(\mathrm{g} / \mathrm{m}^{3}\right)=716 \mathrm{~g} / \mathrm{m}^{3}$;

$\checkmark$ : volume da placa de fluxo $\left(\mathrm{m}^{3}\right)=0,008 \mathrm{~m}^{3}$;

A: área da placa de fluxo $\left(\mathrm{m}^{2}\right)=0,16 \mathrm{~m}^{2}$;

$\Delta \mathrm{C}$ : concentração de metano (ppm);

$\Delta$ t: tempo (h);

MM: massa molar $=16 \mathrm{~g} / \mathrm{mol}$;

P: pressão atmosférica $(\mathrm{mmHg})$;

R: constante do gás ideal $=62,4 \mathrm{mmHg}$

T: temperatura $(K)$.

As concentrações de metano foram determinadas utilizando-se um analisador de gás portátil, tipo Gastech marca Innova. As medidas foram realizadas considerando os seguintes intervalos de tempo: zero minuto, 1 minuto, 2 minutos e 5 minutos, evitando-se a saturação da concentração de metano na placa de fluxo. As concentrações de metano foram obtidas em partes por milhão (ppm) e o cálculo do fluxo de metano foi realizado considerando os seguintes valores de pressão $(761,3 \mathrm{mmHg}$ - março e 759,8 $\mathrm{mmHg}$ - setembro) e temperatura (299,2 K - março e 295,2 K - setembro) medidos em campo, por meio de um analisador de gás portátil Landtec Gem. Os dados obtidos do fluxo de metano foram analisados por meio de análise de variância, utilizando-se o programa computacional estatístico Assistência Estatística Versão 7.7 (Assistat, 2014).

\section{Resultados e discussão}

A Tabela 1 apresenta os resultados obtidos nos ensaios de campo em relação às estimativas do escape fugitivo de metano no aterro sanitário.

\section{Tabela 1 - Fluxo médio de metano por fase do aterro sanitário}

\begin{tabular}{|l|l|}
\hline Fase do aterro sanitário & Fluxo médio de metano $\left(\mathrm{mol} / \mathrm{m}^{2} / \mathrm{h}\right)$ \\
\hline Fase I & $0,04860 \mathrm{a}^{*}$ \\
\hline Fase II & $0,13714 \mathrm{~b}$ \\
\hline Fase III & $0,30668 \mathrm{c}$ \\
\hline Fase IV & $0,39027 \mathrm{~d}$ \\
\hline *as médias seguidas de letras minúsculas distintas diferem entre si ao nível de $5 \%$. \\
\hline
\end{tabular}

fonte: Os autores (2018). 
O fluxo médio de metano no aterro sanitário foi de $0,048 \mathrm{~mol} / \mathrm{m}^{2} / \mathrm{h}$ a $0,39 \mathrm{~mol} / \mathrm{m}^{2} / \mathrm{h}$, apresentando diferença significativa entre as fases. As variações encontradas são relatadas na literatura, indicando que existem vários fatores que interferem na emissão do gás metano pela camada de cobertura do aterro sanitário (Mariano; Jucá, 2010). A diferença relatada fica mais evidente quando se compara o valor obtido da Fase I, por exemplo, com a Fase IV, uma possível explicação seria em função da idade de disposição do resíduo no aterro sanitário, ou seja, a Fase I é a etapa mais antiga, enquanto a Fase IV é a mais recente, o que efetivamente potencializa maior geração de gás metano e consequentemente maior escape fugitivo de metano nas etapas mais recentes em um aterro sanitário (Maciel, 2009). A Figura 5 apresenta a distribuição do escape fugitivo de metano nas distintas fases do aterro sanitário.

\section{Figura 5 - Distribuição do escape fugitivo de metano nas fases do aterro \\ sanitário}

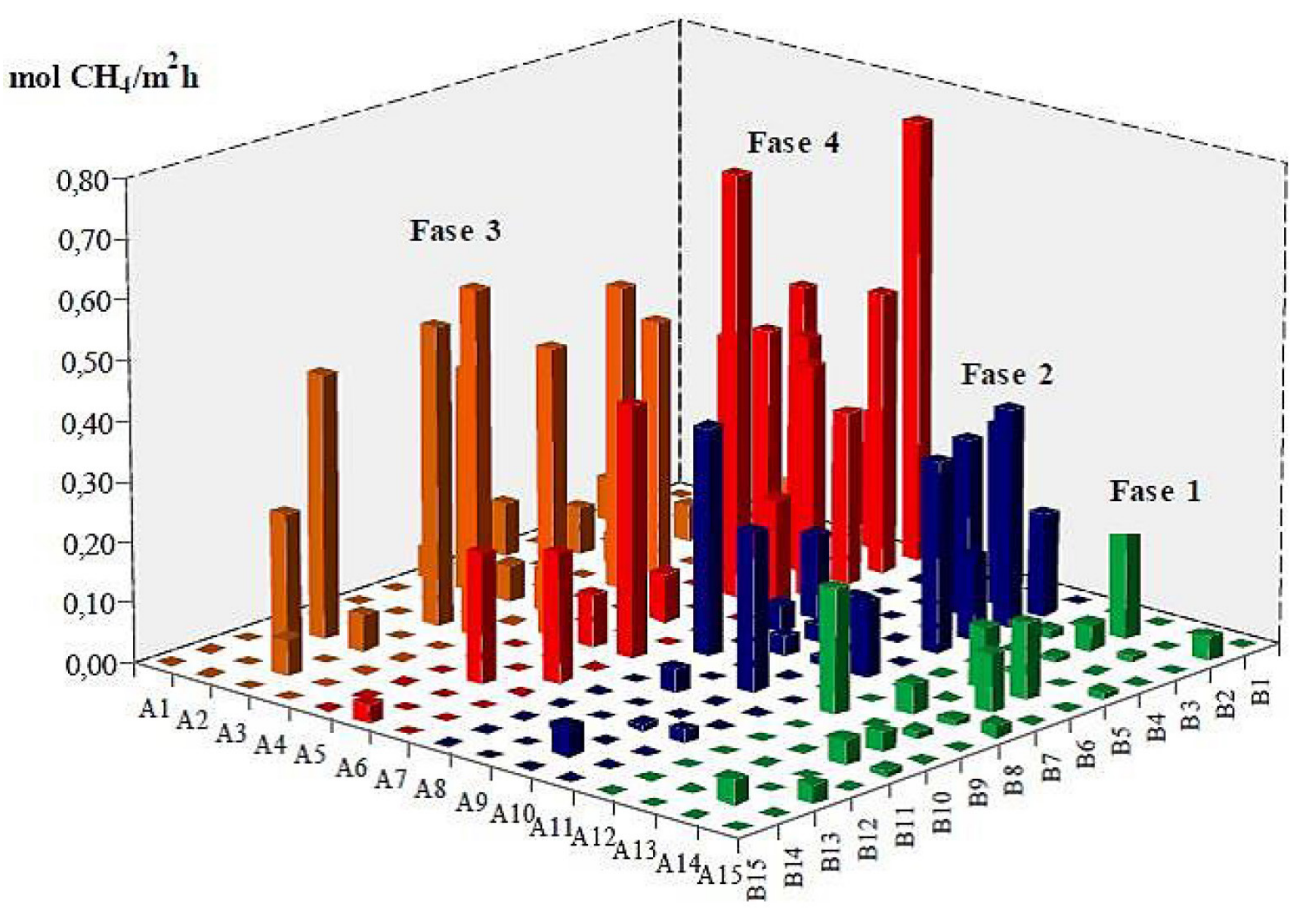

fonte: Acervo pessoal dos autores.

A Tabela 2 apresenta os resultados obtidos do escape fugitivo de gás metano no aterro sanitário considerando os períodos de monitoramento.

\section{Tabela 2 - Fluxo médio de metano por período de monitoramento no ater-} ro sanitário

\begin{tabular}{|l|l|}
\hline Período de monitoramento & Fluxo médio de metano $\left(\mathrm{mol} / \mathrm{m}^{2} / \mathrm{h}\right)$ \\
\hline março/abril & $0,28736 \mathrm{a}^{*}$ \\
\hline setembro/outubro & $0,15398 \mathrm{~b}$ \\
\hline *as médias seguidas de letras minúsculas distintas diferem entre si ao nível de $5 \%$. \\
\hline
\end{tabular}

fonte: Os autores (2018). 
fluxo médio de metano obtido foi maior no período de março-abril do que em setembro-outubro, mostrando que a sazonalidade interfere no escape fugitivo de gás metano no aterro sanitário. Maciel (2003) relata que normalmente períodos com maior pluviometria ocasiona a saturação do solo, reduzindo a emissão fugitiva de metano pela camada de cobertura no aterro sanitário. $\bigcirc$ índice pluviométrico no aterro sanitário, no período de março-abril foi de 162 mm e em setembro-outubro de 277 mm, portanto, a maior umidade favoreceu a redução da emissão fugitiva de metano observada entre os meses de setembro e outubro no aterro sanitário. $\bigcirc$ escape fugitivo de metano no aterro sanitário apresentou variação de $18,66 \mathrm{~g} / \mathrm{m}^{2} / \mathrm{dia}$ a 149,86 g/m²/dia, valores próximos de muitos estudos (Tabela 3).

\section{Tabela 3 - Emissão fugitiva de metano com placa de fluxo em diferentes aterros sanitários}

\begin{tabular}{|l|l|l|}
\hline Local do estudo & Referência & $\begin{array}{l}\text { Emissão fugitiva de } \\
\text { metano }\left(\mathrm{g} / \mathrm{m}^{2} / \text { dia) }\right.\end{array}$ \\
\hline Aterro Tamangapa (Indonésia) & $\begin{array}{l}\text { Lando, Nakayama e Shimaoka } \\
(2017)\end{array}$ & 4,9 a $165,2 \mathrm{~g} / \mathrm{m}^{2} /$ dia \\
\hline Aterro Nuevo Leon (México) & Gonzalez-Valencia et al. (2016) & 10 a $575 \mathrm{~g} / \mathrm{m}^{2} /$ dia \\
\hline Aterro Fakse (Dinamarca) & Scheutz et al. (2009) & 77 a $155 \mathrm{~g} / \mathrm{m}^{2} /$ dia \\
\hline Aterro da Aguazinha-PE (Brasil) & Mariano $(2008)$ & 0,004 a $400 \mathrm{~g} / \mathrm{m}^{2} /$ dia \\
\hline Aterro na Califórnia (EUA) & Abichou et al. (2009) & 0,1 a $175,7 \mathrm{~g} / \mathrm{m}^{2} / \mathrm{dia}$ \\
\hline Aterro da Muribeca-PE (Brasil) & Maciel $(2003)$ & 0,1 a $363 \mathrm{~g} / \mathrm{m}^{2} / \mathrm{dia}$ \\
\hline Aterro Bandeirantes-SP (Brasil) & Silva, Freitas e Candiani $(2013)$ & 0,1 a $148,4 \mathrm{~g} / \mathrm{m}^{2} / \mathrm{dia}$ \\
\hline Aterro de BH-MG (Brasil) & Catapreta (2008) & 23,2 a $337,6 \mathrm{~g} / \mathrm{m}^{2} / \mathrm{dia}$ \\
\hline Aterro Caieiras-SP (Brasil) & Este estudo & 18,6 a $149,8 \mathrm{~g} / \mathrm{m}^{2} / \mathrm{dia}$ \\
\hline
\end{tabular}

fonte: Os autores (2018).

Considerando o fluxo médio de metano por fase do aterro sanitário, foi possível determinar o valor de emissão de metano de cada fase (considerando a área) e a emissão total de metano no aterro sanitário, que foi de 2.196,34 m³/h (Tabela 4).

\section{Tabela 4 - Emissão fugitiva de metano no aterro sanitário}

\begin{tabular}{|l|l|l|l|}
\hline $\begin{array}{l}\text { Fase do aterro } \\
\text { sanitário }\end{array}$ & $\begin{array}{l}\text { Fluxo médio de } \\
\text { metano }\left(\mathrm{m}^{3} / \mathrm{m}^{2} / \mathrm{h}\right)\end{array}$ & $\begin{array}{l}\text { Área da fase do at- } \\
\text { erro sanitário }\left(\mathrm{m}^{2}\right)\end{array}$ & $\begin{array}{l}\text { Fluxo total de } \\
\text { metano }\left(\mathrm{m}^{3} / \mathrm{h}\right)\end{array}$ \\
\hline I & 0,001088 & 55.000 & 59,84 \\
\hline II & 0,003071 & 165.000 & 506,71 \\
\hline III & 0,006869 & 110.000 & 755,59 \\
\hline IV & 0,008742 & 100.000 & 874,2 \\
\hline- & - & - & $2.196,34$ \\
\hline
\end{tabular}

fonte: Os autores (2018). 
A Tabela 5 apresenta um balanço da produção de gás metano no Aterro Sanitário Caieiras. A emissão fugitiva representou $31,4 \%$ do total emitido de gás metano no aterro sanitário, resultado um pouco acima do valor apresentado (22\%) por Maciel e Jucá (2011) estudando o Aterro Sanitário de Aguazinha, no estado de Pernambuco, Brasil. A emissão fugitiva de metano é o resultado da ineficiência do sistema de captação de gás no aterro sanitário.

\section{Tabela 5 - Balanço da Produção de Metano no Aterro Sanitário Caieiras}

\begin{tabular}{|l|l|}
\hline Parâmetros & Valores \\
\hline Número de drenos verticais & 140 \\
\hline Captação total de metano & $7.000 \mathrm{~m}^{3} / \mathrm{h}$ \\
\hline Área total (fases) & $430.000 \mathrm{~m}^{2}$ \\
\hline Emissão total fugitiva de metano & $2.196,34 \mathrm{~m}^{3} / \mathrm{h}$ \\
\hline Emissão fugitiva & $31,4 \%$ \\
\hline Eficiência total & $68,6 \%$ \\
\hline
\end{tabular}

fonte: Os autores (2018).

A eficiência total obtida no Aterro Sanitário Caieiras foi de 68,6\%, valor abaixo do projetado (75\%) pelos gestores do aterro sanitário. Esse resultado corrobora estudos encontrados na literatura, que apontam eficiências de captação de gás em aterro sanitário de aproximadamente 60\% (Spokas et al., 2006).

○ escape fugitivo de metano mostra que os aterros sanitários precisam de aperfeiçoamentos em relação aos seus sistemas de captação de gás e essa emissão não controlada resulta em perda econômica, reduzindo a quantidade de gás metano disponível para a geração de créditos de carbono e, principalmente produção de energia elétrica, além da maior emissão de gases de efeito estufa para a atmosfera.

No Brasil, a Política Nacional de Resíduo Sólido preconiza a valorização ambiental e energética do gás de aterro sanitário, e isso efetivamente pode contribuir para a ampliação do reaproveitamento do biogás, portanto, melhorar a eficiência de captação de gás metano em aterro sanitário, reduzindo o escape fugitivo é de fundamental importância.

Assim, seria de fundamental importância estabelecer algumas ações que podem reduzir o escape fugitivo de gás metano em aterro sanitário, como: melhorar a compactação da camada de cobertura, ampliar o número de drenos verticais, evitar a ocorrência de trincas e fissuras na camada de cobertura e instalar geomembrana na camada de cobertura final.

\section{Conclusões}

Com base nos resultados obtidos neste estudo, pode-se concluir que o escape fugitivo de metano no aterro sanitário foi de $18,66 \mathrm{~g} / \mathrm{m}^{2} /$ dia a $149,86 \mathrm{~g} / \mathrm{m}^{2} /$ dia e o maior escape ocorreu no período de março-abril, em comparação com setembro-outubro, mostrando que a sazonalidade interfere nesse escape. A emissão fugitiva representou 31,4\% do total emitido de gás metano no aterro sanitário, apresentando uma eficiência de captação de 68,6\%, menor do que o valor planejado (75\%) pelos gestores do aterro. 
A ineficiência do sistema de captação amplia o escape fugitivo de gás metano no aterro sanitário, ou seja, emite-se fugitivamente parte daquilo que o sistema construído não foi capaz de captar. $\bigcirc$ uso da técnica da placa de fluxo possibilitou a determinação do escape fugitivo de gás metano pela camada de cobertura do aterro sanitário, subsidiando aperfeiçoamentos para melhorar o sistema de captação de gás metano em aterros.

\section{Referências}

ABICHOU, T. et al. Effects of compost biocovers on gas flow and methane oxidation in a landfill cover. Waste Management, v. 29, n. 5, p. 1595-1601, 2009.

ABRELPE. Associação Brasileira de Empresas de Limpeza Pública e Resíduos Especiais. Panorama dos Resíduos Sólidos no Brasil - 2015. São Paulo: Abrelpe, 2016.

ABREU, F. V. Biogás: economia, regulação e sustentabilidade. Rio de Janeiro: Interciência, 2014. ASSISTAT. Assistência Estatística. Versão 7.7 beta, 2014. Disponível em: http://www. assistat.com. Acesso em: 7 jul. 2014.

BABILOTTE, A. et al. Fugitive methane emissions from landfills: field comparison of five methods on a french landfill. Journal of Environmental Engineering, v. 136, n. 8, p. 777-784, 2010.

BARROS, R. M. Tratado sobre resíduos sólidos: gestão, uso e sustentabilidade. Rio de Janeiro: Interciência, 2013.

BARROS, R. T. V. Elementos de gestão de resíduos sólidos. Belo Horizonte: Tessitura, 2012.

BATTAGLINI, R.; RACO, B.; SCOZZARI; A. Effective monitoring of landfills: flux measurements and thermography enhance efficiency and reduce environmental impact. Journal of Geophysics and Engineering, v. 10, n. 6, p. 1-14, 2013.

BRASIL. Lei no 12.305, de 2 de agosto de 2010. Institui a Política Nacional de Resíduos Sólidos; altera a Lei no 9.605, de 12 de fevereiro de 1998; e dá outras providências. Diário Oficial da União, Brasília, DF, 3 ago. 2010.

CANDIANI, G.; MOREIRA, J. M. L. Estudo da geração de metano em uma célula de aterro sanitário. Jundiaí: Paco, 2015.

CATAPRETA, C. A. A. Comportamento de um aterro sanitário experimental: avaliação da influência do projeto, construção e operação. Tese (Doutorado em Engenharia) - Universidade Federal de Minas Gerais, Belo Horizonte, 2008.

ESSENCIS. Essencis Soluções Ambientais S.A. Relatório Ambiental: CTVA-Caieiras. Caieiras: Essencis, 2016.

GALLEGO, E. et al. Surface emission determination of volatile organic compounds (VOC) from a closed industrial waste landfill using a self-designed static flux chamber. Science of the Total Environment, v. 470-471, p. 587-599, 2014. 
GOLDSMITH JUNIOR, C. D. et al. Methane emissions from 20 landfills across the United States using vertical radial plume mapping. Journal of the Air $\boldsymbol{E}$ Waste Management Association, v. 62, n. 2, p. 183-197, 2012.

GONZALEZ-VALENCIA, R. et al. Hotspot detection and spatial distribution of methane emissions from landfills by a surfasse probe method. Waste Management, v. 55, p. 299-305, 2016.

LANDO, A. T.; NAKAYAMA, H.; SHIMAOKA, T. Application of portable gas detector in point and scanning method to estimate spatial distribution of methane emission in landfill. Waste Management, v. 59, p. 255-266, 2017.

LUCERNONI, F. et al. Use of CFD for static sampling hood design: an example for methane flux assessment on landfill surfaces. Chemosphere, v. 163, p. 259-269, 2016.

MACIEL, F. J.; JUCÁ, J. F. Evaluation of landfill gas production and emissions in a MSW large-scale Experimental Cell in Brazil. Waste Management, v. 31, n. 5, p. 966-977, 2011 .

MACIEL, F. J. Geração de biogás e energia em aterro experimental de resíduos sólidos urbanos. Tese (Doutorado em Engenharia Civil) - Universidade Federal de Pernambuco, Recife, 2009.

MACIEL, F. J. Estudo da geração, percolação e emissão de gases no aterro de resíduos sólidos na Muribeca-PE. Dissertação (Mestrado em Engenharia Civil) Universidade Federal de Pernambuco, Recife, 2003.

MARIANO, M. O. H. Avaliação da retenção de gases em camadas de cobertura de aterros de resíduos. Tese (Doutorado em Engenharia Civil) - Universidade Federal do Pernambuco, Recife, 2008.

MARIANO, M. O. H.; JUCÁ, J. F.T. Ensaios de campo para determinação de emissões de biogás em camadas de cobertura de aterros de resíduos sólidos. Engenharia Sanitária Ambiental, Rio de Janeiro, v. 15, n. 3, p. 223-228, 2010.

MONSTER, J. G. et al. Quantifying methane emission from fugitive sources by combining tracer release and downwind measurements - a sensitivity analysis based on multiple field surveys. Waste Management, v. 34, n. 8, p. 1416-1428, 2014.

PARK, J.-K.; KANG, J.-Y.; LEE, N.-H. Estimation of methane emission flux at landfill surfasse using laser methane detector: Influence of gauge pressure. Waste Management E Research, v. 34, n. 8, p. 784-792, 2016.

SCHEUTZ, C. et al. Quantification of multiple methane emission sources at landfills using a double tracer technique. Waste Management, v. 31, n. 5, p. 1009-1017, 2011.

Microbial methane oxidation processes and technologies for mitigation of landfill gas emissions. Waste Management, v. 27, n. 5, p. 409-455, 2009.

SCHROTH, M. H. et al. Above and below-ground methane fluxes and methanotrophic activity in a landfill-cover soil. Waste Management, v. 32, n. 5, p. 879-889, 2012. 
SILVA, T. N.; FREITAS, F. S. N.; CANDIANI, G. Avaliação das emissões superficiais do gás de aterros sanitários de grande porte. Engenharia Sanitária Ambiental, Rio de Janeiro, v. 18, n. 21, p. 95-104, 2013.

SOUTO, R. D. O papel da geografia em face da crise ambiental. Estudos Avançados, São Paulo, v. 30, n. 87, p. 197-212, 2016.

SPOKAS, K. et al. Methane mass balance at three landfill sites: what is the efficiency of capture by gas collection systems? Waste Management, v. 26, n. 5, p. 516-525, 2006.

TEIXEIRA JUNIOR, L. C. Biogás: alternativa para a geração de energia. Curitiba: Appris, 2016. 